\title{
PENGARUH KEPERCAYAAN, PERSEPSI KEGUNAAN, PERSEPSI KEMUDAHAN, DAN PERSEPSI KENYAMANAN TERHADAP MINAT PENGGUNAAN SISTEM INTERNET BANKING PADA NASABAH BANK MUAMALAT CABANG PEMBANTU MADIUN
}

\author{
Sherly Rakhmawati \\ Isharijadi \\ Pendidikan Akuntansi IKIP PGRI MADIUN \\ Email: sher_own@yahoo.co.id
}

\begin{abstract}
This study purposes to provide evidence of the influence emperis trust, perceived usefulness, perceived ease of use, and perceived enjoyment the interest in the use of internet banking customers of Bank Muamalat Branch Madiun. Samples were taken using purposive sampling method. Data used in this study is primary data in the form of kuesioner. The method used in this study is a quantitative method by using multiple linear analysis and hypothesis testing processed with SPSS version 16.0. Results of data analysis showed that: trust and perceived enjoyment affect the comfort of partial interest in the use of internet banking system, while perceived usefulness and perceived ease of use of partial no effect on the desirability of using internet banking system. And all independent variables simultaneously affect the desirability of using internet banking system.
\end{abstract}

Keywords: trust, perceived usefulness, perceived ease of use, perceived enjoyment, internet banking system.

\begin{abstract}
ABSTRAK
Penelitian ini bertujuan untuk memberikan bukti emperis pengaruh kepercayaan, persepsi kegunaan, persepsi kemudahan, dan persepsi kenyamanaan terhadap minat penggunaan sistem internet banking pada nasabah Bank Muamalat Cabang Pembantu Madiun. Sampel diambil menggunakan metode purposive sampling. Jenis data yang digunakan dalam penelitian ini adalah data primer yang berupa kuesioner. Metode yang digunakan dalam penelitian ini adalah metode penelitian kuantitatif dengan menggunakan teknik analisis linier berganda dan uji hipotesis diolah dengan SPSS versi 16.0. Hasil analisis data menunjukkan bahwa: kepercayaan dan persepsi kenyamanan secara parsial berpengaruh terhadap minat penggunaan sistem internet banking, sedangkan persepsi kegunaan dan persepsi kemudahan secara parsial tidak berpengaruh terhadap minat penggunaan sistem internet banking. Dan seluruh variabel independen berpengaruh secara simultan terhadap minat penggunaan sistem internet banking.
\end{abstract}

Kata kunci: kepercayaan, persepsi kegunaan, persepsi kemudahan, persepsi kenyamanan, sistem internet banking.

\section{PENDAHULUAN}

Internet merupakan salah satu teknologi yang berkembang sangat pesat dan sangat dibutuhkan semua negara untuk membantu kehidupan sehari-hari, tidak terkecuali Indonesia. Dalam daftar yang dirilis oleh Internet Word Stats 
menunjukkan bahwa Indonesia menjadi negara ke-8 sebagai pengakses internet tertinggi di dunia di tahun 2012 (merdeka.com).

Internet pada awalnya merupakan riset yang dilakukan Advanced Research Project Agency pada tahun 1957 yang hanya digunakan untuk kepentingan intern Departemen Pertahanan Amerika, namun akhirnya internet menjadi jaringan yang terhubung secara global. Teknologi internet pertama kali di Indonesia yang tercatat ialah penggunaan protokel internet (IP) yng didaftarkan oleh Universitas Indonesia pada tahun 1988. Dari tahun inilah terus membangkitkan perkembangan internet dimana tahun 1995 barulah internet berkembang sangat pesat di Indonesia. Meskipun demikian pada saat itu pengguna internet sangatlah terbatas sekali, hanya orang-orang tertentulah yang dapat menggunakan layanan internet. Internet pada saat ini tidak hanya dijumpai di kota-kota besar tetapi juga dapat dijumpai di pelosok desa. Hampir semua orang dapat mengakses internet dengan mudah melalui komputer bahkan di genggaman tangan dengan handphone.

Perkembangan teknologi internet tidak hanya berguna untuk hiburan semata, banyak pihak menggunakan internet untuk mengembangkan usaha dan bisnisnya salah satunya adalah lembaga keuangan/perbankan. Dimana hadirnya internet telah menunjang efektifitas dan efisiensi operasional perusahaan, terutama peranannya sebagai sarana komunikasi, publikasi, serta sarana untuk mendapatkan berbagi informasi yang dibutuhkan. Salah satu bentuk layanan publik yang disediakan pihak perbankan untuk melakukan transaksi perbankan melalui teknologi internet adalah online banking atau internet banking. Fitur-fitur yang sering digunakan dalam internet banking antara lain informasi saldo, transfer sesama bank, transfer antar bank, informasi mutasi rekening, pembelian voucher isi ulang pulsa, dan pembayaran tagihan.

Internet banking mulai dirintis perbankan Indonesia sejak tahun 1998. Perintis Internet Banking di Indonesia adalah Bank Papan Sejahtera, yang kemudian disusul oleh Bank Lippo, Bank Intrenational Indonesia (BII), Bank Bali, dan Bank Mega.Keuntungan terbesar dari internet banking adalah nasabah dapat melakukan aktivitas perbankan di manapun dan kapanpun karena nasabah tidak harus secara pribadi mengunjungi bank. Dengan demikian nasabah dapat melakukan penghematan biaya transportasi maupun penghematan waktu. Hal ini disesuaikan dengan perkembangan teknologi dengan gaya hidup nasabah masa kini yang lebih mengutamakan kemudahan dan ketepatan waktu.

Meski fasilitas internet banking menawarkan berbagai manfaat, faktanya minat nasabah untuk menggunakannya masih sangat rendah tercermin dari masyarakat Indonesia lebih menyukai transaksi perbankan secara manual. Disamping itu masih banyak nasabah bank di Indonesia yang menggunakan internet banking hanya sekedar melihat saldo, sehingga nasabah tidak benar-benar merasakan manfaat internet banking. Karena internet banking masih tergolong baru bagi masyarakat, pihak bank haruslah mengetahui faktor-faktor apa saja yang bisa mempengaruhi nasabah dalam menggunakan fasilitas internet banking. Dengan demikian diharapkan dapat memberikan keunggulan bersaing bagi perbankan sendiri.

Banyak bank di Indonesia yang telah menawarkan layanan internet banking untuk dapat memudahkan para nasabah untuk melakukan transaksi sehari-hari, salah satunya adalah bank Muamalat. Bank yang berdiri pada tahun 
1991 marupakan pionir di industri perbankan syariah Tanah Air yang terlihat sangat serius berinvestasi untuk mengembangkan internet banking miliknya. Karena layanan yang disediakan oleh bank yang akan berusia 22 tahun pada 1 november ini setiap tahunnya semakin membaik meskipun masih jauh tertinggal dengan bank syariah dan konvensional lain. Pada internet banking Muamalat terbaru nasabah sudah bisa melakukan transfer ke seluruh bank, pembelian pulsa isi ulang, dan pembayaran tagihan walaupun masih sangat terbatas.

Berdasarkan fenomena yang terjadi, peneliti ingin mengetahui apa saja persepsi individu yang berpengaruh terhadap minat penggunaan sistem internet banking. Penelitian ini mengacu pada penelitian sebelumya, yaitu penelitian yang dilakukan oleh Sartika dan Zaki (2013) tentang pengaruh kepercayaan, persepsi kegunaan, persepsi kemudahan, dan persepsi kenyamanan terhadap minat penggunaan sistem internet banking. Dari penelitian ini, terdapat empat variabel yang dapat mempengaruhi minat penggunaan sistem internet banking, yaitu kepercayaan, persepsi kegunaan, persepsi kemudahan, dan persepsi kenyamanan. Subjek penelitian terdapat di kota Malang, dengan populasinya adalah mahsiswa Akuntansi yang ada di Universitas Brawijaya Malang Fakultas Ekonomi dan Bisnis sebanyak 1.041 orang dan sampel yang dipilih adalah 289 orang yang menggunakan metode convenience sampling serta dihitung menggunakan rumus slovin dalam menghasilkan jumlah sampelnya. Penelitian ini merupakan pengembangan dari penelitian sebelumnya dimana peneliti ingin lebih memfokuskan penelitian terhadap fasilitas layanan internet banking yang ada pada Bank Muamalat Cabang Pembantu Madiun.

\section{TELAAH LITERATUR}

Chau dan Lai (2003) dalam studi empirisnya yang berjudul "An Empirical Investigation of the Determinants of user Acceptance of Internet Banking", bertujuan untuk mengetahui faktor-faktor personalization, alliance services, task familiarity, accessibility, perceived usefulness, dan perceived ease of use yang mempengaruhi keputusan pelanggan dalam mengadopsi layanan internet banking. Metode analisis yang digunakan adalah Structural Equation Modeling (SEM) pada perangkat lunak Lisrel 8.30. Hasil penelitian menunjukkan secara khusus personalization, alliance services, task familiarity, dan accessibility ditemukan memiliki signifikan pengaruh terhadap perceived usefulness, dan perceived ease of use. Dan ditemukan pula perceived usefulness, dan perceived ease of use menjadi faktor penting dalam membina sikap positif terhadap menerima jasa.

Arif Wibowo (2007) dalam studi empirisnya yang berjudul "Kajian Tentang Perilaku Pengguna Sistem Informasi Dengan Pendekatan Technology Acceptance Model (TAM)", bertujuan untuk mengkaji faktor-faktor perceived ease of use, perceived usefulness, attitude toward using, behavioral intention to use, dan actual system usage dalam perilaku pengguna sistem informasi. Metode analisis yang digunakan adalah Structural Equation Modeling (SEM) pada perangkat lunak Lisrel 8.30. Hasil penelitian menunjukkan perceived ease of use berpengaruh terhadap perceived usefulness, perceived usefulness berpengaruh terhadap attitude toward using, perceived ease of use tidak berpengaruh terhadap attitude toward using, attitude toward using berpengaruh terhadap behavioral 
intention to use, perceived usefulness berpengaruh terhadap behavioral intention to use, dan behavioral intention to use berpengaruh terhadap actual system usage.

Hardi dan Dwi (2007) dalam studi empirisnya yang berjudul "Determinan Pengadopsian Layanan Internet Banking: Perspektif Konsumen Perbankan Daerah Istimewa Yogyakarta", bertujuan untuk mengetahui faktorfaktor personalisasi, jasa aliansi, kefamiliaran tugas, kemampuan akses, persepsi manfaan, dan persepsi kemudahan penggunaan dalam sikap penentuan jasa. Metode analisis yang digunakan adalah Structural Equation Modeling (SEM) pada perangkat lunak AMOS versi 6.0. Hasil penelitian menunjukkan hanya 4 hubungan yang secara statistik signifikandan bertanda positif yaitu: jasa aliansi terhadap persepsi manfaat, kesesuaian tugas terhadap persepsi manfaat, kesesuaian tugas terhadap persepsi kemudahan, dan persepsi kemudahan penggunaan terhadap sikap.

Qureshi et al. (2008) dalam studi empirisnya yang berjudul "Customer Acceptance of Online Banking in Developing Economies", bertujuan untuk mengevaluasi penerimaan pelanggan perbankan online dengan variabel penelitian perceived usefulness, perceived ease of use, perceived enjoyment, the amount of information, security and privacy, internet connection. Metode analisis yang digunakan adalah statistik regresi dan korelasi. Hasil penelitian menunjukkan perceived usefulness, perceived ease of use, perceived enjoyment, dan security and privace merupakan alasan inti dari klien bergeser dari perbankan tradisional ke sistem perbankan online.

Sauca Ananda (2009) dalam studi empirisnya yang berjudul "Analisis Faktor - Faktor Yang Mempengaruhi Minat Nasabah Bank Bca Untuk Menggunakan Klik-BCA”, bertujuan untuk menganalisis faktor-faktor apa saja yang mempengaruhi minat nasabah BCA untuk menggunakan Klik BCA, dengan variabel penelitian yaitu: variabel independen berupa kemudahan penggunaan (ease fo use), kenyamanan (convenience), kepercayaan (trust), dan ketersediaan fitur (feature avaiability), sedangkan variabel dependen yaitu minat untuk menggunakan (intention to use). Analisis dilakukan dengan menggunakan SPSS versi 17.0. Hasil penelitian adalah kemudahan penggunaan (ease of use) tidak berpengaruh signifikan positif terhadap minat untuk menggunakan (intention to use), sedangkan kenyamanan (convenience), kepercayaan (trust), dan ketersediaan fitur (feature avaiability) masing-masing berpengaruh signifikan positif terhadap minat untuk menggunakan (intention to use).

Gilang Rizky (2010) dalam studi empirisnya yang berjudul "Pengaruh Persepsi Teknologi Informasi, Kemudahan, Resiko Dan Fitur Layanan Terhadap Minat Ulang Nasabah Bank Dalam Menggunakan Internet Banking (Studi Pada Nasabah Bank Bca)", bertujuan untuk menganalisis dan memperoleh bukti atas pengaruh persepsi teknologi, kemudahan dalam menggunakan, resiko, dan fitur layanan terhadap minat ulang nasabah dalam menggunakan internet banking. Analisis dilakukan dengan menggunakan SPSS versi 13.0. Hasil penelitian ini menunjukkan bahwa persepsi teknologi, kemudahan dalam menggunakan, resiko, dan fitur layanan berpengaruh terhadap minat ulang nasabah dalam menggunakan internet banking.

Totok dan Mudiantono (2011) dalam studi empirisnya yang berjudul “ Analisis Pengaruh Trust dan Mutu E-Banking Terhadap Minat bertransaksi Ulang Secara Online (Studi Kasus Nasabah BNI Semarang)", bertujuan untuk 
mengetahui pengaruh trust dan mutu e-banking terhadap minat bertransaksi ulang secara online. Analisis dilakukan dengan menggunakan SPSS versi 17.0. Hasil penelitian ini menunjukkan trust dan mutu e-banking berpengaruh signifikan terhadap minat bertransaksi online.

Iramadhani dan Mahendra (2011) dalam studi empirisnya yang berjudul “ Pengaruh Persepsi Kebermanfaatan, Persepsi Kemudahan Penggunaan Dan Computer Self Efficacy Terhadap Penggunaan Online Banking Pada Mahasiswa S1 Fakultas Ekonomi Universitas Negeri Yogyakarta", bertujuan untuk mengetahui pengaruh persepsi kebermanfaatan, persepsi kemudahan penggunaan dan computer self efficacy terhadap penggunaan online banking pada mahasiswa S1 Fakultas Ekonomi Universitas Negeri Yogyakarta. Metode analisis yang digunakan adalah analisis regresi sederhana dan analisis regresi berganda dengan SPSS versi 17.0. Hasil penelitian ini menunjukkan persepsi kebermanfaatan berpengaruh positif dan signifikan terhadap penggunaan online banking, persepsi kemudahan penggunaan berpengaruh positif dan signifikan terhadap penggunaan online banking, dan computer self efficacy berpengaruh positif dan signifikan terhadap penggunaan online banking. Persepsi kebermanfaatan, persepsi kemudahan penggunaan dan computer self efficacy secara bersama-sama berpengaruh positif dan signifikan terhadap penggunaan online banking.

Sartika dan Zaki (2013) dalam studi empirisnya yang berjudul "Pengaruh Kepercayaan, Persepsi Kegunaan, Persepsi Kemudahan, Dan Persepsi Kenyamanan Terhadap Minat Penggunaan Sistem Internet Banking", bertujuan untuk menguji faktor-faktor yang mempengaruhi minat untuk menggunakan layanan internet banking dengan memodifikasi model Technology Acceptance Model (TAM). Analisis dilakukan dengan menggunakan software Smart PLS. Hasil penelitian menunjukkan konstruk sikap berpengaruh terhadap minat untuk menggunakan layanan internet banking, serta konstruk kepercayaan dan persepsi kenyamanan berpengaruh terhadap minat untuk menggunakan layanan internet banking. Sebaliknya konstruk persepsi kegunaan dan persepsi kemudahan tidak berpengaruh terhadap minat untuk menggunakan layanan internet banking.

\section{HIPOTESIS}

$\mathrm{H}_{1}$ : Kepercayaan (trust) berpengaruh signifikan terhadap minat penggunaan sistem internet banking.

$\mathrm{H}_{2}$ : Persepsi kegunaan (perceived usefulness) berpengaruh signifikan terhadap minat penggunaan sistem internet banking.

$\mathrm{H}_{3}$ : Persepsi kemudahan (perceived ease of use) berpengaruh signifikan terhadap minat penggunaan sistem internet banking.

$\mathrm{H}_{4}$ : Persepsi kenyamanan (perceived enjoyment) berpengaruh signifikan terhadap minat penggunaan sistem internet banking.

$\mathrm{H}_{5} \quad$ : Kepercayaan (trust), persepsi kegunaan (perceived usefulness), persepsi kemudahan (perceived ease of use), persepsi kenyamanan (perceived enjoyment) berpengaruh signifikan terhadap minat penggunaan sistem internet banking.

\section{METODE PENELITIAN}

Penelitian ini yang mengambil sampel 100 nasabah Bank Muamalat Cabang Pembantu Madiun ini termasuk pada penelitian expost facto yaitu 
penelitian di mana variabel-variabel bebas telah terjadi ketika peneliti mulai dengan pengamatan variabel terikat dalam suatu penelitian. Sampel diambil dengan menggunakan teknik sampel bertujuan, dimana sampel dipilih karena terdapat tujuan tertentu. Pemilihan sampel ini dilandasi bahwa nasabah yang bersangkutan pernah dan ingin menggunakan layanan internet banking.

Pengumpulan data dalam penelitian ini menggunakan metode kuesioner, dimana kuesioner merupakan metode pengumpulan data yang dilakukan dengan cara memberi seperangkat pertanyaan atau pertanyaan tertulis kepada responden untuk dijawabnya.

\section{ANALISIS DATA}

Analisis data menggunakan program SPSS (Statistical Package for the Social Science) for windows versi 16.0, dengan tahap-tahap sebagai berikut:

a. Uji Kualitas Data

1. Uji Validitas Instrument

Validitas instrumen dapat diartikan bahwa instrumen tersebut dapat memberikan suatu nilai yang sesungguhnya dari masalah yang hendak dikaji. Pengujian validitas tiap butir digunakan analisis item, yaitu mengkorelasikan skor tiap butir dengan skor total yang merupakan jumlah skor tiap butir (Sugiyono, 2010: 187). Kuesioner dikatakan valid apabila $\mathrm{r}^{\text {hitung }}>\mathrm{r}^{\text {tabel }}$.

2. Uji Reliabilitas

Reliabilitas merupakan indeks yang menunjukkan sejauh mana suatu alat pengukur dipercaya atau dapat diandalkan. Adapun cara mengetahui seberapa tingkat reliabilitas dari suatu instrumen dapat dilakukan pengujian pada masing-masing data dari variabel terkait. Suatu konstruk atau variabel dikatakan reliabel jika memberikan nilai Cronbach Alpha> 0,70 (Nunnally dalam Imam Ghozali, 2012: 48).

b. Uji Asumsi Klasik

1. Uji Normalitas

Normalitas merupakan suatu distribusi yang menunjukkan sebaran data yang seimbang sebagian besar data berada pada nilai di tengah. Pada prinsipnya normalitas dapat diditeksi dengan melihat penyebaran data (titik) pada sumbu diagonal dari grafik atau dengan melihat histogram dari residualnya (Imam Ghozali, 2012: 163).

2. Uji Multikoloniearitas

Uji multikoloniearitas adalah pengujian untuk mengetahui ada tidaknya korelasi yang signifikan antar variabel-variabel independen dalam model regresi linier berganda. Untuk mendeteksi ada tidaknya multikolonieritas dalam model regresi dapat digunakan VIF dan lawannya Tolerance. Nilai cutoff yang biasa dipakai untuk menunjukkan adanya multikolonieritas adalah nilai Tolerance $\leq 0,10$ atau sama dengan nilai VIF $\geq 10$ (Imam Ghozali, 2012: 106).

3. Uji Heteroskedasitas

Uji heteroskedastisitas digunakan untuk mengetahui ada atau tidaknya penyimpangan asumsi klasik heteroskedastisitas yaitu adanya ketidaksamaan varian dari residual untuk semua pengamatan pada model 
regresi. Model regresi yang baik adalah yang Homoskedatisitas atau tidak terjadi heterokedastisitas (Imam Ghozali, 2012: 139).

4. Uji Autokorelasi

Uji autokorelasi bertujuan untuk menguji apakah model regresi linier ada korelasi antara kesalahan pengganggu pada periode $t$ dengan kesalahan pengganggu pada periode t-1 (sebelumnya) (Imam Ghozali, 2012: 110). Untuk menditeksi ada tidaknya autokorelasi peneliti menggunakan uji Durbin Watson.

c. Analisis Linier Berganda

Persamaan regresi dapat dirumuskan sebagai berikut (Sugiyono, 2010: 261):

$\mathrm{Y}=\mathrm{a}+\mathrm{b}_{1} \mathrm{X}_{1}+\mathrm{b}_{2} \mathrm{X}_{2}+\mathrm{b}_{3} \mathrm{X}_{3}+\mathrm{b}_{4} \mathrm{X}_{4}+\mathrm{e}$

Dimana:

$\begin{array}{ll}\mathrm{Y} & =\text { Minat } \\ \mathrm{A} & =\text { Konstanta } \\ \mathrm{b}_{1}, \mathrm{~b}_{2}, \mathrm{~b}_{3}, \mathrm{~b}_{4} & =\text { Koefisien regresi } \\ \mathrm{X}_{1} & =\text { Kepercayaan } \\ \mathrm{X}_{2} & =\text { Kegunaan } \\ \mathrm{X}_{3} & =\text { Kemudahan } \\ \mathrm{X}_{4} & =\text { Kenyamanan }\end{array}$

d. Pengujian Hipotesis

1. Koefisien Determinasi $\left(\mathrm{R}^{2}\right)$

Koefisisen determinasi $\left(R^{2}\right)$ pada intinya mengukur seberapa jauh kemampuan model dalam menerangkan variasi variabel terikat (Mudrajad Kuncoro, 2007: 84).

2. Uji Signifikansi Parsial (t-test)

Pada dasarnya uji t menunjukkan seberapa jauh pengaruh satu variabel penjelas secara individual dalam menerangkan variasi variabel terikat (Mudrajad Kuncoro, 2007: 81).

3. Uji Signifikasi Simultan (F test)

Pada dasarnya uji f menunjukkan apakah semua variabel bebas yang dimasukkan dalam model mempunyai pengaruh secara bersama-sama terhadap variabel terikat (Mudrajad Kuncoro, 2007: 82).

\section{ANALISIS HASIL DAN PEMBAHASAN}

a. Uji Kualitas Data

1. Uji Validitas

Uji validitas dilakukan dengan bantuan software statistik yaitu SPSS 16.0. Dalam penelitian ini pengujian dilakukan terhadap 100 responden. Variabel kepercayaan, persepsi kegunaan, persepsi kemudahan, persepsi kenyamanan, dan minat telah lolos uji validitas data.

2. Uji Reliabilitas

Uji reliabilitas dilakukan dengan bantuan software statistik yaitu SPSS 16.0. Dalam penelitian ini pengujian dilakukan terhadap 100 responden. Dengan dasar pengambilan keputusan jika nilai Cronbach Alpha lebih dari 0,70 dinyatakan reliabel. Adapun hasil pengolahan data terdapat pada tabel dibawah ini: 
Tabel 1. Hasil Uji Reliabilitas

\begin{tabular}{|l|c|c|}
\hline \multicolumn{1}{|c|}{ Variabel } & Nilai Alpha & Status \\
\hline Kepercayaan & 0,738 & Reliabel \\
\hline Persepsi Kegunaan & 0,732 & Reliabel \\
\hline Persepsi Kemudahan & 0,716 & Reliabel \\
\hline Persepsi Kenyamanan & 0,737 & Reliabel \\
\hline Minat Penggunaan Sistem Internet Banking & 0,853 & Reliabel \\
\hline
\end{tabular}

Sumber: Data Primer yang diolah, 2013

Berdasarkan Tabel 6 di atas dapat terlihat bahwa seluruh variabel penelitian memiliki nilai Cronbach Alpha yang lebih besar dari 0.70 sehingga dapat disimpulkan bahwa semua variabel yang digunakan dalam penelitian ini berstatus reliabel.

b. Uji Asumsi Klasik

1. Uji Normalitas

Berdasarkan hasil analisis dengan menggunakan program SPSS 16.0. Apabila pada gafik normal plot dapat terlihat jika data menyebar disekitar garis diagonal dan mengikuti arah garis diagonal, maka regresi memenuhi asumsi normalitas begitu pula sebaliknya.

\section{Gambar 1}

\section{Normal P-P Plot of Regression Standardized Residual}

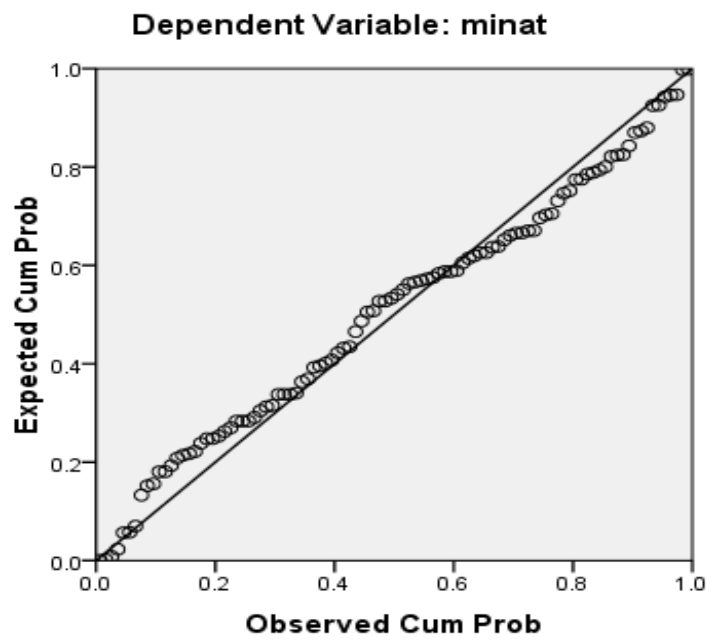

Jika dilihat berdasarkan grafik 1 di atas, maka dari semua data berdistribusi normal kerena semua data menyebar mengikuti garis diagonal dan mengikuti arah garis diagonalnya.

2. Uji Multikoloniearitas

Berdasarkan hasil analisis dengan menggunakan program SPSS 16.0. Untuk mendeteksi ada tidaknya multikolonieritas dalam model regresi dapat digunakan VIF dan lawannya Tolerance. Nilai cutoff yang biasa dipakai untuk menunjukkan adanya multikolonieritas adalah nilai Tolerance $\leq 0,10$ atau sama dengan nilai $\mathrm{VIF} \geq 10$. 
Tabel 2. Hasil Uji Multikolonieritas

\begin{tabular}{|l|r|l|}
\hline Variabel & Tolerance & \multicolumn{1}{l|}{ VIF } \\
\hline Kepercayaan & 0.43 & 2.328 \\
\hline Kegunaan & 0.443 & 2.256 \\
\hline Kemudahan & 0.504 & 1.983 \\
\hline Kenyamanan & 0.502 & 1.993 \\
\hline
\end{tabular}

Jika dilihat berdasarkan tabel 2 dapat disimpulkan model regresi tersebut tidak terdapat problem multikolonieritas. Maka model regresi yang ada layak untuk dipakai.

\section{Uji Heteroskedasitas}

Berdasarkan hasil analisis dengan menggunakan program SPSS 16.0. Jika terdapat pola tertentu, seperti titik-titik yang ada membentuk pola tertentu yang terartur (bergelombang, melebar kemudian menyempit), maka mengindikasikan telah terjadi heteroskedastisitas dan begitu pula sebaliknya.

Gambar 2

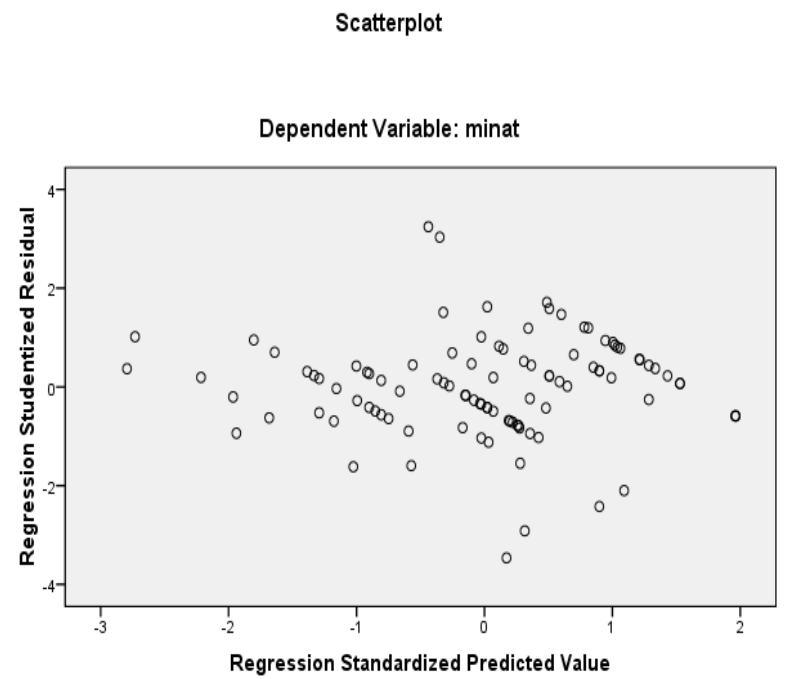

Dari grafik 2 di atas terlihat titik-titik yang menyebar secara acak, tidak membentuk suatu pola tertentu yang jelas, serta tersebar baik di atas maupun di bawah angka 0 pada sumbu Y. Sehingga modal regresi ini tidak terjadi heterokedastisitas dan layak dipakai untuk memprediksi minat nasabah.

4. Uji Autokorelasi

Berdasarkan hasil analisis diperoleh nilai DW hitung 1.853, sedangkan dari tabel DW dengan signifikansi 0.05 dan jumlah data $(\mathrm{n})=100$, serta $\mathrm{k}$ $=4$ diperoleh nilai $\mathrm{du}=1.758$, dan $4-\mathrm{du}=2.242$. Sehingga nilai $\mathrm{du}<\mathrm{dw}$ $<4-$ du $(1,758<1,853<2,242)$ dapat disimpulkan bahwa tidak terdapat autokorelasi. 
c. Analisis Linier Berganda

Berdasarkan hasil pengujian SPSS 16.0, diperoleh hasil regresi sebagai berikut :

Tabel 3.Hasil Analisis Linier Berganda

\begin{tabular}{|c|c|c|c|c|c|c|}
\hline & \multirow[t]{2}{*}{ Model } & \multicolumn{2}{|c|}{$\begin{array}{c}\text { Unstandardized } \\
\text { Coefficients }\end{array}$} & \multirow{2}{*}{$\begin{array}{c}\text { Standardized } \\
\text { Coefficients }\end{array}$} & \multirow[t]{2}{*}{$\mathrm{t}$} & \multirow{2}{*}{ Sig. } \\
\hline & & B & Std. Error & & & \\
\hline \multirow[t]{5}{*}{1} & (Constant) & -.286 & 1.279 & & -.224 & .823 \\
\hline & kepercayaan & .647 & .093 & .604 & 6.983 & .000 \\
\hline & Kegunaan & -.023 & .096 & -.020 & -.240 & .811 \\
\hline & Kemudahan & .125 & .090 & .112 & 1.397 & .166 \\
\hline & kenyamanan & .308 & .085 & .290 & 3.621 & .000 \\
\hline
\end{tabular}

a. Dependent Variable: minat

$Y^{\prime}=-0,286+0.647 \mathrm{X}_{1}-0,023 \mathrm{X}_{2}+0,125 \mathrm{X}_{3}+0,308 \mathrm{X}_{4}$

d. Pengujian Hipotesis

1. Koefisien Determinansi $\left(\mathrm{R}^{2}\right)$

Berdasarkan hasil analisis dengan menggunakan program SPSS 16.0. diperoleh hasil sebagai berikut:

Tabel 4. Hasil Uji $\mathrm{R}^{2}$

Model Summary

\begin{tabular}{|c|c|r|r|r|}
\hline Model & $\mathrm{R}$ & R Square & $\begin{array}{c}\text { Adjusted R } \\
\text { Square }\end{array}$ & $\begin{array}{c}\text { Std. Error of the } \\
\text { Estimate }\end{array}$ \\
\hline 1 & $.823^{\mathrm{a}}$ & .677 & .663 & 1.517 \\
\hline
\end{tabular}

Dari Tabel 4.19 nilai koefisien determinai yang disesuaikan (Adjusted $R^{2}$ ) adalah 0,663 artinya $66,3 \%$ semua variabel independent dapat menerangkan variabel dependent, sisanya 33,7\% dipengaruhi oleh faktor lain di luar model penelitian.

2. Uji Signifikansi Parsial (t-test)

Berdasarkan hasil analisis dengan menggunakan program SPSS 16.0. diperoleh hasil uji t pada tabel 3, yang dapat dijelaskan sebagai berikut:

\section{1) H1 : Kepercayaan (trust) berpengaruh signifikan terhadap} minat penggunaan sistem internet banking.

Dari hasil perhitungan didapat nilai $\mathrm{t}^{\text {hitung }}$ sebesar 6,983 dan $\mathrm{t}^{\text {tabel }}$ dicari pada $\alpha=5 \%: 2=2,5 \%$ (uji 2 sisi) dengan derajat kebebasan (df) $n-k-1$ atau $100-4-1=95$. Dengan pengujian ini diperoleh $\mathrm{t}^{\text {tabel }}$ sebesar 1,984 . Oleh karena itu $\mathrm{t}^{\text {hitung }}>\mathrm{t}^{\text {tabel }}(6,983>1,984)$, maka Ha diterima dan Ho ditolak.

Kesimpulannya, variabel kepercayaan $\left(\mathrm{X}_{1}\right)$ berpengaruh signifikan terhadap minat penggunaan internet banking $(\mathrm{Y})$, hal ini dapat dilihat dari probabilitas signifikansi untuk $\mathrm{X}_{1}$ sebesar 0,000 lebih kecil dari nilai alpha sebesar 0,05. Sehingga kepercayaan perpengaruh signifikan terhadap minat penggunaan internet banking.

Hal ini konsisten dengan penelitian yang dilakukan oleh Sauca Ananda (2009), Totok dan Mudianto (2011), serta Sartika dan Zaki (2013). 


\section{2) $\mathrm{H2}$ : Persepsi kegunaan (perceived usefulness) berpengaruh signifikan terhadap minat penggunaan sistem internet banking.}

Dari hasil perhitungan didapat nilai $\mathrm{t}^{\text {hitung }}$ sebesar $-0,240$ dan $\mathrm{t}^{\text {tabel }}$ dicari pada $\alpha=5 \%: 2=2,5 \%$ (uji 2 sisi) dengan derajat kebebasan (df) n - k - 1 atau $100-4-1=95$. Dengan pengujian ini diperoleh $\mathrm{t}^{\text {tabel }}$ sebesar 1,984 . Oleh karena itu $\mathrm{t}^{\text {hitung }}<\mathrm{t}^{\text {tabel }}(-0,240<1,984)$, maka Ha ditolak dan Ho diterima.

Kesimpulannya, variabel persepsi kegunaan $\left(\mathrm{X}_{2}\right)$ tidak berpengaruh signifikan terhadap minat penggunaan internet banking (Y), hal ini dapat dilihat dari probabilitas signifikansi untuk $\mathrm{X}_{2}$ sebesar 0,811 lebih besar dari nilai alpha sebesar 0,05. Sehingga persepsi kegunaan tidak perpengaruh signifikan terhadap minat penggunaan internet banking.

Hasil ini konsisten dengan penelitian yang dilakukan Hardi dan Dwi (2007) serta Sartika dan Zaki (2013).

3) H3 : Persepsi kemudahan (perceived ease of use) berpengaruh signifikan terhadap minat penggunaan sistem internet banking.

Dari hasil perhitungan didapat nilai $\mathrm{t}^{\text {hitung }}$ sebesar 1,397 dan $\mathrm{t}^{\text {tabel }}$ dicari pada $\alpha=5 \%: 2=2,5 \%$ (uji 2 sisi) dengan derajat kebebasan (df) $n-k-$ 1 atau $100-4-1=95$. Dengan pengujian ini diperoleh $t^{\text {tabel }}$ sebesar 1,984. Oleh karena itu $\mathrm{t}^{\text {hitung }}<\mathrm{t}^{\text {tabel }}(1,397<1,984)$, maka Ha ditolak dan Ho diterima.

Kesimpulannya, variabel persepsi kemudahan $\left(\mathrm{X}_{3}\right)$ tidak berpengaruh signifikan terhadap minat penggunaan internet banking (Y), hal ini dapat dilihat dari probabilitas signifikansi untuk $\mathrm{X}_{3}$ sebesar 0,166 lebih besar dari nilai alpha sebesar 0,05 . Sehingga persepsi kemudahan tidak perpengaruh signifikan terhadap minat penggunaan internet banking.

Hal ini konsisten dengan penelitian yang dilakukan oleh Sauca Ananda (2009) serta Iramadhani dan Mahendra (2012).

\section{4) H4 : Persepsi kenyamanan (perceived enjoyment) berpengaruh signifikan terhadap minat penggunaan sistem internet banking.}

Dari hasil perhitungan didapat nilai $\mathrm{t}^{\text {hitung }}$ sebesar 3,621 dan $\mathrm{t}^{\text {tabel }}$ dicari pada $\alpha=5 \%: 2=2,5 \%$ (uji 2 sisi) dengan derajat kebebasan (df) $n-k-$ 1 atau $100-4-1=95$. Dengan pengujian ini diperoleh $t^{\text {tabel }}$ sebesar 1,984 . Oleh karena itu $\mathrm{t}^{\text {hitung }}>\mathrm{t}^{\text {tabel }}(3,621>1,984)$, maka Ha diterima dan Ho ditolak.

Kesimpulannya, variabel persepsi kenyamanan $\left(\mathrm{X}_{4}\right)$ berpengaruh signifikan terhadap minat penggunaan internet banking $(\mathrm{Y})$, hal ini dapat dilihat dari probabilitas signifikansi untuk $\mathrm{X}_{4}$ sebesar 0,000 lebih kecil dari nilai alpha sebesar 0,05 . Sehingga persepsi kenyamanan perpengaruh signifikan terhadap minat penggunaan internet banking.

Hal ini konsisten dengan penelitian yang dilakukan oleh Qureshi et al (2008). 
3. Uji Signifikasi Simultan (F test

Berdasarkan hasil analisis dengan menggunakan program SPSS 16.0. diperoleh hasil sebagai berikut:

Tabel 11. Hasil Uji F

\begin{tabular}{|l|l|r|r|r|r|r|}
\hline \multicolumn{2}{|c|}{ Model } & \multicolumn{1}{c|}{$\begin{array}{c}\text { Sum of } \\
\text { Squares }\end{array}$} & df & Mean Square & F & \multicolumn{1}{c|}{ Sig. } \\
\hline \multirow{2}{*}{1} & Regression & 469.792 & 4 & 117.448 & 53.975 & $.000^{\mathrm{a}}$ \\
\cline { 2 - 7 } & Residual & 206.718 & 95 & 2.176 & & \\
\cline { 2 - 7 } & Total & 676.510 & 99 & & & \\
\hline
\end{tabular}

a. Predictors: (Constant), kenyamanan, kegunaan, kemudahan, kepercayaan

b. Dependent Variable: minat

5) H4 : Kepercayaan (trust), persepsi kegunaan (perceived usefulness), persepsi kemudahan (perceived ease of use), persepsi kenyamanan (perceived enjoyment) berpengaruh signifikan terhadap minat penggunaan sistem internet banking.

Dari hasil perhitungan didapat nilai $\mathrm{F}^{\text {hitung }}$ sebesar 53,975 dan dengan tingkat keyakinan $95 \%, \alpha=5 \%$, df $1=4$, df $2(\mathrm{n}-\mathrm{k}-1)$ atau $(100-4$ $1=95)$, sehingga $\mathrm{F}^{\text {tabel }}$ diperoleh sebesar 2,47. Oleh karena itu $\mathrm{F}^{\text {hitung }}>$ $F^{\text {tabel }}(53,975>2,470)$, maka Ha diterima dan Ho ditolak.

Kesimpulannya, variabel Kepercayaan $\left(\mathrm{X}_{1}\right)$, persepsi kegunaan $\left(\mathrm{X}_{2}\right)$, persepsi kemudahan $\left(\mathrm{X}_{3}\right)$, persepsi kenyamanan $\left(\mathrm{X}_{4}\right)$ berpengaruh signifikan terhadap minat penggunaan internet banking $(\mathrm{Y})$, hal ini dapat dilihat dari probabilitas signifikansi untuk variabel independent sebesar 0,000 lebih kecil dari nilai alpha sebesar 0,05.

\section{KESIMPULAN}

1. Kepercayaan berpengaruh positif dan signifikan terhadap minat penggunaan sistem internet banking. Apabila kepercayaan nasabah terhadap bank ditingkatkan, maka akan diikuti dengan meningkatnya minat penggunaan sistem internet banking. Dan sebaliknya jika kepercayaan nasabah terhadap bank menurun, maka akan diikuti dengan menurunnya minat penggunaan sistem internet banking.

2. Persepsi kegunaan tidak berpengaruh positif dan signifikan terhadap minat penggunaan sistem internet banking. Apabila kegunaan sistem internet banking ditingkatkan atau pun menurun, maka tidak akan diikuti dengan peningakatan ataupun penurunan minat penggunaan sistem internet banking.

3. Persepsi kemudahan tidak mempunyai pengaruh positif dan signifikan terhadap minat penggunaan sistem internet banking. Apabila kemudahan sistem internet banking ditingkatkan atau pun menurun, maka tidak akan diikuti dengan peningakatan ataupun penurunan minat penggunaan sistem internet banking. 
4. Persepsi kenyamanan mempunyai pengaruh positif dan signifikan terhadap minat penggunaan sistem internet banking. Apabila kenyamanan nasabah terhadap bank ditingkatkan, maka akan diikuti dengan meningkatnya minat penggunaan sistem internet banking. Dan sebaliknya jika kenyamanan nasabah terhadap bank menurun, maka akan diikuti dengan menurunnya minat penggunaan sistem internet banking.

5. Kepercayaan, persepsi kegunaan, persepsi kemudahan, dan persepsi kenyamanan secara bersama-sama mempunyai pengaruh positif dan signifikan terhadap minat penggunaan sistem internet banking.

\section{SARAN}

1. Variabel kepercayaan berpengaruh positif terhadap minat penggunaan sistem internet banking, maka diharapkan perusahan harus berusaha untuk membangun, meningkatkan, dan menjaga kepercayaan nasabah. Dan beberapa cara yang dapat dilakukan Bank Muamalat adalah dengan terus memperkuat keamanan sistem dan jaringan serta selalu memegang komitmen terhadap nasabah.

2. Persepsi kegunaan tidak memiliki pengaruh positif terhadap minat penggunaan internet banking, maka diharapkan Bank Muamalat berusaha meningkatkan kegunaan yang akan diperoleh nasabah selama menggunakan intenet banking, sehingga nasabah mendapatkan kegunaan internet banking yang lebih luas. Untuk itu Bank Muamalat dapat melakukan sosialisasi yang lebih mendetail mengenai kegunaan dan manfaat dari internet banking kepada calon nasabah agar layanan ini dapat digunakan lebih maksimal.

3. Tidak adanya keterkaitan pengaruh antara persepsi kemudahan terhadap minat penggunaan internet banking, maka sebaiknya Bank Muamalat lebih giat lagi memberikan informasi tentang kemudahan internet banking. Hal ini dapat dilakukan dengan mempromosikan fasilitas internet banking, baik dengan brosur maupun penawaran langsung kepada nasabah.

4. Terdapat pengaruh positif antara persepsi kenyamanan dengan minat penggunaan internet banking, untuk itu Bank Muamalat harus berusaha untuk memperluas dan mempertahankan tingkat kenyamanan agar nasabah tidak kembali menggunakan cara konvensional.

\section{DAFTAR PUSTAKA}

Gilang Rizky Amijaya. 2010. Pengaruh Persepsi Teknologi Informasi, Kemudahan, Resiko dan Fitur Layanan Terhadap Minat Ulang Nasabah Bank dalam Menggunakan Internet Banking (Studi Pada Nasabah Bank $B C A$ ). Skripsi tidak diterbitkan. Semarang: Fakultas Ekonomi Universitas Diponegoro.

Hadri Kusuma dan Dwi Susilowati. 2007. Determinan Pengadopsian Layanan Internet Banking Perspektif Konsumen Perbankan Daerah Istimewa Yogyakarta. Jurnal Akuntansi dan Auditing Indonesia (Online), Volume 11, No. 2: 105-124, (http://journal.uii.ac.id, Diunduh 5 April 2013). 
Imam Ghozali. 2012. Aplikasi Analisis Multivariate dengan Program IBM SPSS 20. Semarang: Badan Penerbit Universitas Diponegoro.

Iramadhan \& Mahendra A.N. 2012. Pengaruh Persepsi kebermanfatan, Persepsi Kemudahan Penggunaan dan Computer Self Efficacy Terhadap Penggunaan Online Banking Pada Mahasiswa S1 Fakultas Ekonomi Universitas Negeri Yogyakarta. Journal UNY (Online), Vol. 1, No. 3, (http://www.journal.uny.ac.id, Diunduh 5 April 2013).

Mudrajad Kuncoro. 2007. Metode Kuantitatif. Yogyakarta: UPP STIM YKPN.

Sartika Sari Ayu Tjini dan Zaki Baridwan. 2013. Pengaruh Kepercayaan, Persepsi Kegunaan, Persepsi Kemudahan, dan Persepsi Kenyamanan Terhadap Minat Penggunaan Sistem Internet Banking. Jurnal Imliah Mahasiswa FEB (Online), Vol. 1, No. 2, (http://www.jimfeb.ub.ac.id, Diunduh 5 April 2013).

Sauca Ananda Pranidana. 2009. Analisis Faktor-faktor yang Mempengaruhi Minat Nasabah Bank BCA Menggunakan Klik-BCA. Skripsi tidak diterbitkan. Semarang: Fakultas Ekonomi Universitas Diponegoro.

Sugiyono. 2010. Metode Penelitian Pendidikan (Pendekatan Kuantitatif, Kualitatif, dan $R \& D)$. Bandung: CV Alfabeta.

Chau, P.Y.K. and Lai, V.S.K. 2003. An Empirical investigation of the determinants of user acceptansce of internet banking. Journal of Organizational Computing \& Electrocic Commerce. Vol. 13 No. 2, pp. 123-145

Qureshi, T.M., Zafar, M.K. and Khan, M. B. 2008. Customer Acceptance of Online Banking in Developing Economies. Journal of Internet Banking and Commerce. Vol. 13, No.1. 